\title{
BMJ Open Analysis of age-sex and deprivation stratified trends in assault deaths in Scotland (1974-2015) to identify age, period or cohort effects
}

\author{
Jane Parkinson (D) , Jon Minton, Gerry McCartney
}

To cite: Parkinson J, Minton J, McCartney G. Analysis of age-sex and deprivation stratified trends in assault deaths in Scotland (1974-2015) to identify age, period or cohort effects. BMJ Open 2020;10:e030064. doi:10.1136/ bmjopen-2019-030064

- Prepublication history and additional material for this paper are available online. To view these files, please visit the journal online (http://dx.doi. org/10.1136/bmjopen-2019030064).

Received 28 February 2019 Revised 04 July 2019 Accepted 08 July 2019
Check for updates

(c) Author(s) (or their employer(s)) 2020. Re-use permitted under CC BY-NC. No commercial re-use. See rights and permissions. Published by BMJ.

Public Health Observatory, NHS Health Scotland, Meridian Court, 5 Cadogan Street, Glasgow, G2 6QE, UK

Correspondence to Dr Jane Parkinson; jane.parkinson@nhs.net

\section{ABSTRACT}

Objectives Mortality rates in Scotland are higher, and health inequalities are greater, than in the rest of Western and Central Europe. There was a marked divergence during the 1980s and 1990s in the Scottish rates partly due to rises in alcohol-related and drug-related deaths, suicide and deaths by assault. This study examines whether age, period or cohort effects account for the trends in death by assault in Scotland and any sex or deprivation inequalities in these.

Design We calculated crude and age-standardised mortality rates for deaths by assault for Scottish men and women from 1974 to 2015 for the population overall and for populations stratified by Carstairs area of deprivation. We examined age-sex stratified trends to identify obvious age-period-cohort effects.

Setting This study was conducted in Scotland.

Participants Men and women whose registered death by the International Classification of Diseases was due to assault from 1974 to $2015(n=3936)$ were included in this study.

Results Whereas age-standardised mortality rates from this cause fell gradually for women since 1974, for men they increased in the early 1990s and remained higher until around 2006, before falling. Death by assault was substantially more common among men aged around 15-50 years and in the most deprived areas. There was little change in the age groups most impacted over time, which made cohort effects unlikely. A period effect for the 15 years until 2006, with a consistent age-sex-area deprivation patterning, was evident.

Conclusions Mortality due to assault in Scotland is unequally felt, with young men living in the most deprived areas suffering the highest rates. There is a 15 -year period effect up until 2006, impacting on young men as an age-period interaction, with no obvious cohort effects. Exploration of the demographics of criminological data may identify age, period or cohort effects among perpetrators of assault.

\section{INTRODUCTION}

Around 1950, the rate of improvement in Scotland's mortality started to lag behind that of the rest of Britain and other Western European countries, and some areas experienced an increase in mortality rates in the
Strengths and limitations of this study

- This study uses a complete record of all deaths in Scotland occurring over a long time period (1974-2015).

- Deaths are carefully coded using the International Classification of Diseases and recorded as individual digital records which provides a robust dataset to examine.

- There were insufficient deaths by assault to present more detailed visual analysis or to undertake detailed statistical modelling and the conclusions are based primarily on descriptive analyses of aggregated age groups and periods.

- Aggregating across periods to reduce fluctuations in the data means that such incidents that cause a noticeable increase in deaths by assault in a specific year can appear of prominence across a time period.

- Our analysis focused on the victims rather than perpetrators of assaults who could display different age, period or cohort effects. Exploration of the demographics of criminological data (such as conviction rates by sex, age and year) may be able to illuminate further.

1980s. ${ }^{12}$ Scotland now has higher mortality rates and wider health inequalities than the rest of Western Europe. ${ }^{13}$ Since 1981, less of the higher mortality compared with England and Wales has been able to be explained by area deprivation. ${ }^{45}$ This excess mortality (ie, after accounting for deprivation), slower rate of improvement in mortality and greater health inequalities have been attributed to higher mortality from alcohol-related and drug-related deaths, violence (assault) and suicide (particularly in young adults) and higher mortality from heart disease, stroke and cancer throughout adulthood. ${ }^{67}$

Using age, period, cohort (APC) analysis to seek to understand the reasons behind the trends in these health outcomes, we have previously shown age-period interactions in the rise and fall of alcohol-related deaths ${ }^{8}$ 
and cohort effects and sex-area deprivation interactions in the recent trends in suicide and drug-related deaths. ${ }^{9} 10$ The latter cohort effects support an emerging hypothesis to explain the excess mortality in Scotland, namely that there is a greater vulnerability in Scotland to exposure to economic and social changes resulting from political changes of the 1980 s. $^{7}$

Although there are a number of existing epidemiological studies considering trends in deaths due to assault, none look for age, period and cohort effects. ${ }^{11}$ This is important because cohort effects can remain hidden unless these are specifically sought. ${ }^{12} 13$

In this paper, we extend this exploration of APC patterns in external causes of death and the existing epidemiological analysis of deaths from assault in Scotland to consider whether age, period or cohort effects may be present in the trends in death due to assault since 1974 and whether there are inequalities by sex or deprivation.

\section{METHODS}

\section{Data sources}

Data on the number of deaths due to assault by sex, single year of age at death, year of registration of death and postcode of residence for Scotland from 1974 to 2015 were obtained from the National Records of Scotland (NRS) $(\mathrm{n}=3936)$. Deaths were coded by International Classification of Diseases 8 (ICD 8) E960-E969 for 1974-1978 and by ICD 9 E960-E969 for 1979-1999 for deaths where the underlying cause was homicide and injury purposely inflicted by other persons and by ICD 10 X85-Y09 and Y87.1 for 2000 onward for deaths where the underlying cause was assault or sequelae of assault, collectively referred to in this paper as deaths due to assault. Deaths due to the Lockerbie bombing of December 1988, coded as assault by other specific explosive E9658 ( $n=267)$, were subsequently excluded. Data manipulation was performed using IBM SPSS Statistics V.19 and Microsoft Excel 2013.

Analyses by deprivation were based on Carstairs area deprivation scores (calculated using data from the nearest census on the prevalence of male unskilled social class, housing overcrowding, unemployment and car ownership) for postcode sectors, which were then ranked and divided into fifths (quintiles, where quintile $1=$ most deprived and quintile $5=$ least deprived) ${ }^{14}$ Carstairs look-up files were obtained from Information Services Division Scotland (ISD) and deaths assigned to a Carstairs deprivation category. Cases with no associated Carstairs scores $(n=217)$ were removed from the analyses by deprivation.

Mid-year population estimates for Scotland by sex and single year of age, from age 0 to $90+$ years, were obtained from NRS. These are produced as official statistics and certified by the independent UK Statistics Authority as 'National Statistics', and clear governance, robust methodological procedures and quality assurance processes exist to ensure data quality. ${ }^{1516}$ Population data

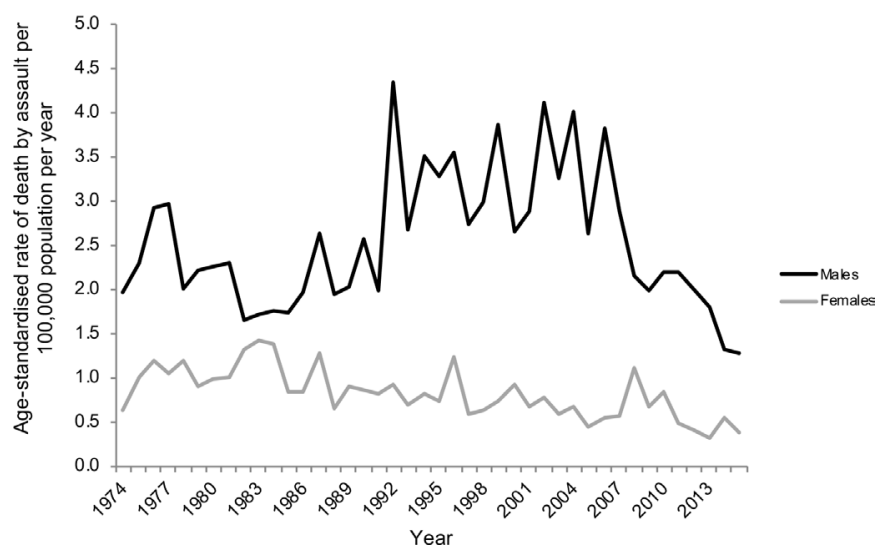

Figure 1 Age-standardised rate of death by assault per 100000 population per year in Scotland, 1974-2015, by sex.

by Carstairs area deprivation, from age 0 to $85+$ years, were obtained from ISD with interpolation between the censuses following robust methodological procedures. The age structure of the population data determined the upper age limit for analyses so analyses were restricted to those aged $0-90+$ years, or aged $0-85+$ years for the deprivation analysis. Subsequent to our analysis, a revision was made by NRS in their Scottish mid-year population estimates for 2002-2010, which affected the age distribution for those aged 81 years and above (see https:// www.nrscotland.gov.uk/files//statistics/population-estimates/mid-year-corrections/correction-to-age-distribution-mid-year-pop-estimates-2002-2010.pdf). Analysis involving repeating the analysis for figures 1 and 2 with the revised population dataset showed that the revision in the population dataset had no effect on our results and conclusions drawn.

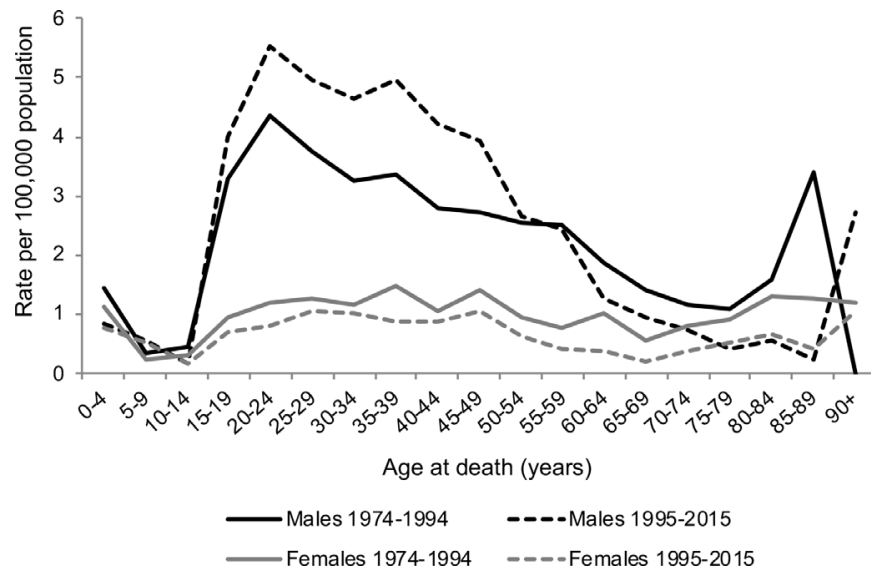

Figure 2 Age distribution of crude rates of death by assault per 100000 population per year in Scotland over periods 1974-1994 and 1995-2015 combined data, by sex. * *These age profiles show general trends with age across two time periods 1974-1994 and 1995-2015 and will have been affected by any age-period-cohort effects occurring during those periods. 


\section{Patient and public involvement statement}

This study used deidentified secondary data. Patients were not involved in this study.

\section{Descriptive analysis}

We calculated age-standardised mortality rates for all ages from 1974 to 2015 by sex using the 2013 European Standard Population. For age effects analysis, data from 1974 to 1994 and data from 1995 to 2015 were separately combined for presentation of crude death rates by 5 -year age groups (from 0-4 years to $90+$ years) for age at death by sex. Further age effects investigation involved analysis of crude death rates by specified age groups for 3-year periods from 19741976 to 2013-2015.

For analysis by area deprivation, age-standardised mortality rates for all ages from 1974 to 2015 by sex and Carstairs quintile were calculated using the 2013 European Standard Population. Age effects investigation for men by area deprivation involved analysis of crude death rates by specified age groups for 3-year periods from 1974-1976 to 2013-2015.

We visually inspected trends to identify obvious ageperiod-cohort effects.

\section{RESULTS}

\section{Trends over time}

Age-standardised rates for assault deaths were higher among men than women for the entire period from 1974 to 2015 (figure 1). Rates among men fell from 1974 to the mid-1980s, rose slightly until 1991, after which they increased rapidly and fluctuated at this higher level until 2006, and thereafter have steadily fallen. Rates for women in contrast have gradually fallen over the period.

\section{Age effects}

Rates of deaths by assault are patterned by age for both men and women (figure 2). Among men, rates were highest for those aged 20-24 years, falling steadily with increasing age until rising again among those over 80 . Between 1974-1994 and 1995-2015, the age profile for men did not change markedly, although higher rates extended across those aged 20-49 years in the later period and were lower for those aged $60+$ years. There was some fluctuation among the oldest age groups over time. The age profile for women differed from that for men for both periods with an absence of a peak in rates for those aged 20-24 years and all rates except that for those aged 5-9 years were lower over the 1995-2015 period.

The contribution of men aged 15-49 years to the increase in male mortality rate by assault from 19921994 to the end of 2004-2006 is clear from the agestratified trend data (online supplementary figure S1), with a greater contribution from those aged 15-29 years (figure 3).

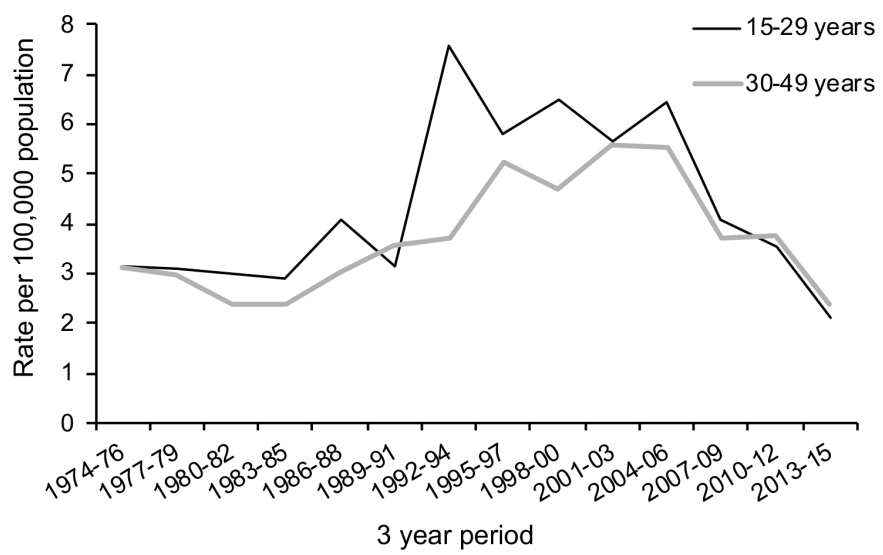

Figure 3 Crude rates of death by assault per 100000 population per 3-year periods in Scotland, 1974-2015, for men aged 15-29years and 30-49years.

\section{Inequalities by area deprivation}

Deaths by assault for men are very unequal by area deprivation, with the overall rise in mortality during the late 1980s and the fall in the late 2000s almost entirely due to a rise and fall in the most deprived areas (figure 4 and supplementary figure S2). There are also inequalities by area deprivation in deaths from assault among women, but these are much less than for men.

The deprivation gradient for deaths by assault among men is largely a result of the distribution of deaths for those aged 15-49 years (figure 5).

\section{DISCUSSION}

\section{Main results}

Rates of death by assault are greater among men than women over the period 1974-2015. Death rates increased dramatically for men from the start of the 1990s and remained elevated until 2006, and have since fallen. Those for women remained low and gradually fell over the period. Men of around 15-50 years of age substantially contribute to the higher rates observed among men and young adult men especially to the period of elevated death rate from the mid-1980s. The age groups most impacted did not change markedly over time, making cohort effects unlikely (see also online supplementary figure S3). Deaths by assault are very unequal and the rise in rate of death for men between the start of the 1990s and the mid-2000s is clearly driven by deaths in the two most deprived quintiles. The results for men reflect a 15-year age-period interaction effect evident for a specific sexarea deprivation group.

\section{Strengths and weaknesses of the analysis}

We used individual digital records that were introduced by NRS in 1974. These include deaths for the whole population, for which causes have been determined by medical practitioners and then carefully coded, following robust procedures ${ }^{17}$ thus providing a complete record of all deaths in Scotland over the time period and a robust and long time series to examine the potential for APC effects. 

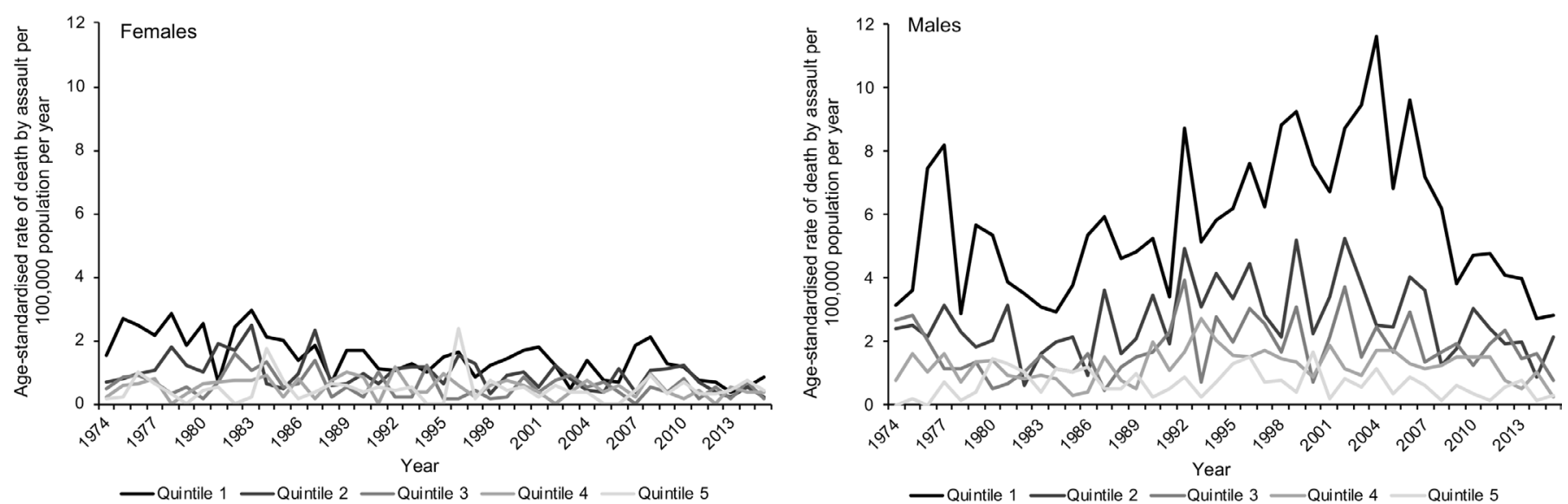

Figure 4 Age-standardised rate of death by assault per 100000 population per year in Scotland, 1974-2015, by sex and Carstairs quintile. ${ }^{*}$ Quintile $1=$ most deprived and Quintile $5=$ least deprived.

Coding changes over the time series would have had no impact on deaths identified as being due to assault. Both ICD 8 and ICD 9 are comparably coded as E960969 'Homicide and injury purposely inflicted by other persons', and analysis by NRS has shown that the change from ICD 9 to ICD $10 \mathrm{did}$ not impact numbers. ${ }^{18}$ Our deprivation analysis used Carstairs deprivation indices, which are widely used and allow for analysis by deprivation pre-1996. Based on the census, they are therefore founded on robust underlying data but are limited by the availability of relevant census data and the size of the postcode sectors on which they are based. ${ }^{19}$

A consequence of the small number of deaths is that incidents that cause a noticeable increase in deaths by assault in a specific year will be evident in the data and appear of prominence causing the trends to fluctuate. Aggregating across periods to reduce the fluctuations in the data means that such incidents can appear of prominence across a time period rather than just a single year. While both of these are evident in our analysis, we do not feel that these consequences of dealing with small numbers affect our overall APC conclusions and the trends observed, although it does mean that there is a level of uncertainty around interpreting trends for specific individual ages. While coded as deaths due to assault, we removed deaths resulting from the Lockerbie bombing of December 1988 (which involved an aircraft crash in Scotland from an overflying aeroplane in which a bomb exploded) as these were unrelated to the deaths due to assault in Scotland that were the focus of this research and had a noticeable effect on the results. The small number of deaths also means that there were insufficient deaths by assault to present Lexis surface plots of age-year specific rates by age in a single year or to undertake formal statistical modelling of the data stratified by APC, using intrinsic estimator (IE) regression modelling, which overcomes the mathematical codependence of APC effects that negates the use of simple regression models, as we have previously undertaken for suicide and alcohol-related and drug-related deaths. ${ }^{8-10}$ These methods require a level of disaggregation which would likely be disclosive, 'noisy' and too underpowered to clearly identify APC patterns and for IE modelling.

Additionally, disentangling APC effects is problematic, and while the IE modelling is a newer approach to statistical estimation, which overcomes the mathematical
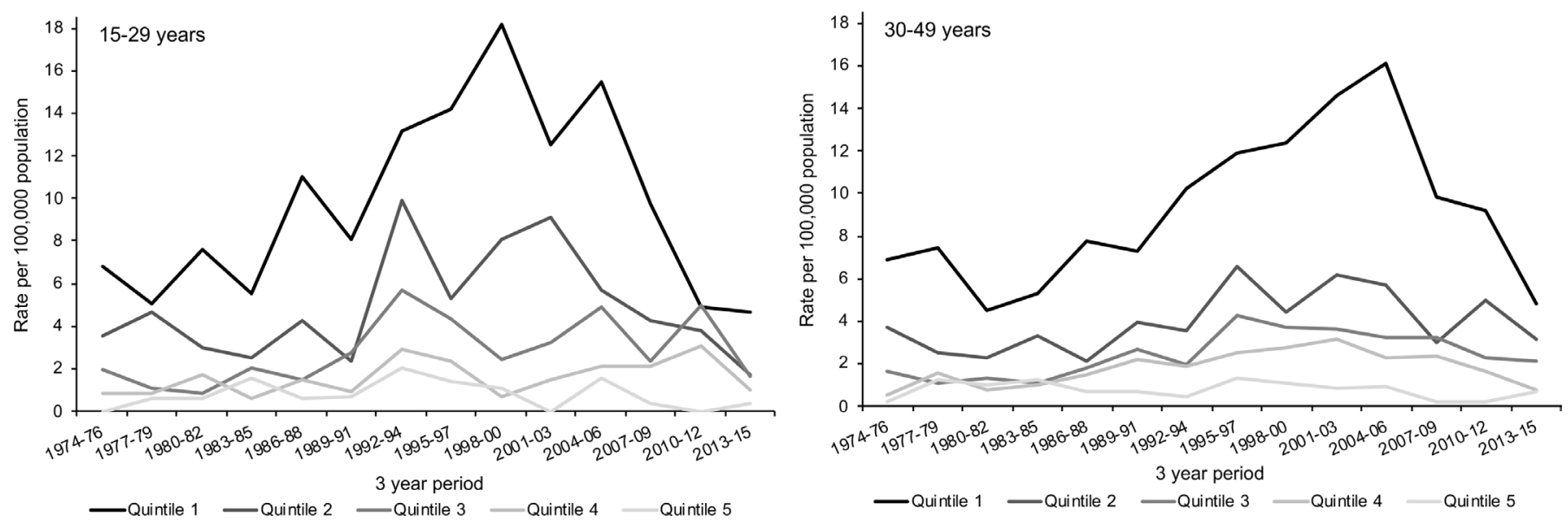

Figure 5 Crude rates of death by assault per 100,000 population per 3-year periods in Scotland, 1974-2015, for men aged 1529 years and $30-49$ years by Carstairs quintile ${ }^{*}$ Quintile $1=$ most deprived and Quintile $5=$ least deprived. 
codependence of APC effects that negates the use of simple regression models, it still has limitations. ${ }^{10}{ }^{20}$ For instance, if used, cohort IE estimates especially would need to be interpreted with caution because there are limited observations for the first and last cohorts and also as we have limited information for each birth cohort across their entire lifecourse. This can lead to the age effects observed being misattributed by the IE model to a cohort effect. As a result, the conclusions in relation to APC effects are primarily based on the descriptive analyses of aggregated age groups and periods.

Our analysis looks at mortality in deaths due to assault and therefore the victims rather than the perpetrators of assaults. It may be that an APC analysis of perpetrators may be more likely to display cohort effects.

\section{Comparison with other studies}

Our results are consistent with and extend previous research demonstrating the most pronounced increase in death by assault for men aged 15-44 years in Scotland from 1980 to 2005, and the persistently higher rates for men and in more deprived areas. ${ }^{11}{ }^{21}$ This is very similar to the sociodemographic patterning of penetrating injuries found across the UK. ${ }^{22}$

Male death rates by assault are dominated by deaths due to a sharp object, most notably a knife, and has accounted for around $50 \%$ of all homicides in the last 10 years. ${ }^{23}$ Increases in deaths due to sharp objects have been shown to have contributed to the increase in deaths by assault observed over the period 1980-2005 and will have largely contributed to the period effect we identified. ${ }^{11} 24$ The rate of homicides involving knives being especially high in Glasgow, a city with areas of high deprivation. Similar to our findings, the incident of assault-related sharp force injury is also higher among younger people, men and those living in areas of social deprivation. ${ }^{25}$ This incident rate has also been falling since 2009, most marked among younger age groups. ${ }^{25}$

The rise in mortality due to assault occurred at a similar time to the rise in alcohol-related and drug-related mortality and suicide in Scotland, all of which have been attributed to the changing political and social conditions of the 1980s. ${ }^{7}$ There has been some suggestion that the recent decline in deaths from assault as we observed may be due to 'a public health approach' to violence, knife crime and gang culture adopted by the Violence Reduction Unit which was created by Strathclyde police in 2005 and later rolled out across Scotland. ${ }^{26-28}$ Laws around the carrying of knives were also extended in $2006 .{ }^{26}$ However, there is little evaluative evidence available to ascertain what, if any, contribution these initiatives had. Understanding the context of multiple deprivation, and the gendered environment in which violence occurs, and addressing these through a 'maximum diversionary approach', is evidenced as being effective at addressing (particularly youth) violence. ${ }^{29} 30$

\section{Implications and conclusions}

Mortality due to assault is substantially more common among young men in deprived areas than for women, at older ages or for people living in less deprived areas. Mortality rates, and inequalities, increased markedly in the early 1990s and remained high until the mid-2000s before subsequently falling, but the age profile of victims changed little over time. There is therefore evidence of age and period effects, but little evidence of cohort effects, in deaths due to assault in Scotland. The 15-year period effect is likely to be due to similar factors that were behind the rise and fall of alcohol-related mortality, ${ }^{8}$ the causes of which relate to a vulnerable population encountering a changed political, economic and social situation from the early 1980s which created a period of high unemployment, high income inequality and disinvestment from deprived communities. ${ }^{7}$

Acknowledgements We would like to thank Julie Ramsay and Frank Dixon at the National Records of Scotland for the dataset and for advising on details of Scottish deaths due to assault statistics, and also David Readhead and Laura Kate Campbell at NHS National Services Scotland for assistance in providing data by deprivation groupings.

Contributors GM generated the initial idea for the study. Analyses of data were conducted by JP. JP interpreted the data and drafted the manuscript. Both JM and GM provided critical input into the interpretation of the data and intellectual content to the redrafting of the manuscript. All authors read and approved the final draft.

Funding The authors have not declared a specific grant for this research from any funding agency in the public, commercial or not-for-profit sectors.

Competing interests None declared.

Patient consent for publication Not required.

Ethics approval No ethical approval was required or sought for the analyses in this paper. The data for the research were obtained from an existing database containing details of Scottish deaths from 1974 held by the National Records of Scotland (NRS). All requirements specified for the use of this dataset by the NRS were adhered to. The data are anonymised and presented disaggregated only by age and year independently for each gender, rather than by both age and year in combination (as in a Lexis surface plot). The age and year categories used are also not disaggregated by single years/years of age. With this level of disaggregation, the individuals cannot be deidentified, but the broader trends are still apparent.

Provenance and peer review Not commissioned; externally peer reviewed.

Data availability statement The original data used for this study are owned by the NRS and can be obtained by researchers from them on request. No additional data are available.

Open access This is an open access article distributed in accordance with the Creative Commons Attribution Non Commercial (CC BY-NC 4.0) license, which permits others to distribute, remix, adapt, build upon this work non-commercially, and license their derivative works on different terms, provided the original work is properly cited, appropriate credit is given, any changes made indicated, and the use is non-commercial. See: http://creativecommons.org/licenses/by-nc/4.0/.

ORCID iD

Jane Parkinson http://orcid.org/0000-0002-5697-1645

\section{REFERENCES}

1 McCartney G, Walsh D, Whyte B, et al. Has Scotland always been the 'sick man' of Europe? An observational study from 1855 to 2006. Eur J Public Health 2012;22:756-60.

2 Norman P, Boyle P, Exeter D, et al. Rising premature mortality in the UK's persistently deprived areas: Only a Scottish phenomenon? Soc Sci Med 2011;73:1575-84.

3 Popham F, Boyle P. Assessing socio-economic inequalities in mortality and other health outcomes at the Scottish national level: Final report. Edinburgh: Scottish Collaboration for Public Health Research and Policy, 2011.

4 Hanlon P, Lawder RS, Buchanan D, et al. Why is mortality higher in Scotland than in England and Wales? Decreasing influence of 
socioeconomic deprivation between 1981 and 2001 supports the existence of a 'Scottish Effect'. J Public Health 2005;27:199-204.

5 Schofield L, Walsh D, Munoz-Arroyo R, et al. Dying younger in Scotland: trends in mortality and deprivation relative to England and Wales, 1981-2011. Health Place 2016;40:106-15.

6 McCartney G, Collins C, Walsh D, et al. Accounting for Scotland's excess mortality: towards a synthesis. Glasgow: Glasgow Centre for Population Health, 2011

7 Walsh D, McCartney G, Collins C, et al. History, politics and vulnerability: explaining excess mortality in Scotland and Glasgow. Glasgow: Glasgow Centre for Population Health, 2016.

8 McCartney G, Bouttell J, Craig N, et al. Explaining trends in alcoholrelated harms in Scotland, 1991-2011 (I): the role of incomes, effects of socio-economic and political adversity and demographic change. Public Health 2016;132:13-23.

9 Parkinson J, Minton J, Lewsey J, et al. Recent cohort effects in suicide in Scotland: a legacy of the 1980s? J Epidemiol Community Health 2017;71:194-200.

10 Parkinson J, Minton J, Lewsey J, et al. Drug-related deaths in Scotland 1979-2013: evidence of a vulnerable cohort of young men living in deprived areas. BMC Public Health 2018;18:357-65.

11 Leyland $\mathrm{AH}$, Dundas R. The social patterning of deaths due to assault in Scotland, 1980-2005: population-based study. J Epidemiol Community Health 2010;64:432-9.

12 Minton J, Vanderbloemen L, Dorling D. Visualizing Europe's demographic scars with coplots and contour plots. Int J Epidemiol 2013;42:1164-76.

13 Minton J, Shaw R, Green MA, et al. Visualising and quantifying 'excess deaths' in Scotland compared with the rest of the UK and the rest of Western Europe. J Epidemiol Community Health 2017;71:461-7.

14 Carstairs V, Morris R. Deprivation: explaining differences in mortality between Scotland and England and Wales. BMJ 1989;299:886-9.

15 NRS. Information on the quality assurance arrangements for administrative data used in population estimates. Edinburgh: National Records Of Scotland, 2016.

16 NRS. Mid-2018 population estimates for scotland: methodology guide. Edinburgh: National Records of Scotland, 2019.
17 NRS. Quality of national records of Scotland (NRS) data on deaths, 2019. Available: https://www.nrscotland.gov.uk/statistics-anddata/statistics/statistics-by-theme/vital-events/deaths/deathsbackground-information/quality-of-nrs-data-on-deaths [Accessed 2 May 2019].

18 General Register Office for Scotland. Registrar general for Scotland annual report 2000. Edinburgh: National Records of Scotland, 2001.

19 ISD Scotland. Carstairs - Problems with the use of area classifications. Edinburgh: ISD Scotland, 2013.

20 Yang Y, Schulhofer-Wohl S, Fu WJ, et al. The intrinsic estimator for Age-Period-Cohort analysis: what it is and how to use it. Am J Sociol 2008;113:1697-736.

21 McGuffie AC, Graham CA, Beard D, et al. Scottish urban versus rural trauma outcome study. J Trauma 2005;59:632-8. doi:10.1097/01.ta. $0000186543.47450 .6 f$

22 Whittaker G, Norton J, Densley J, et al. Epidemiology of penetrating injuries in the United Kingdom: a systematic review. Int J Surg 2017;41:65-9.

23 Scottish Government. Homicide in Scotland 2017-18. Edinburgh: Scottish Government, 2018.

24 Leyland $\mathrm{AH}$. Homicides involving knives and other sharp objects in Scotland, 1981-2003. J Public Health 2006;28:145-7.

25 Goodall CA, MacFie F, Conway DI, et al. Assault-related sharp force injury among adults in Scotland 2001-2013: incidence, sociodemographic determinants and relationship to violence reduction measures. Aggress Violent Behav 2019;46:190-6.

26 McCallum F. Knife crime, SPICe Briefing. Edinburgh: The Scottish Parliament, 2011.

27 Younge G, Barr C. How Scotland reduced knife deaths among young people. The Guardian, 2017.

28 Kmietowicz Z. Glasgow gang members offered way out of violent lifestyle. BMJ 2008;337:a2972.

29 McAra L, McVie S. Maximum diversion, minimum intervention: key messages from the Edinburgh study of youth transitions and crime. in justice for young people. The Howard League research medal, 2013.

30 McAra L, McVie S. Understanding youth violence: the mediating effects of gender, poverty and vulnerability. J Crim Justice 2016;45:71-7. 